\title{
Laser Micro Welding Of Nitinol for Cardiovascular Applications
}

\author{
Rashmi M. Raju' ${ }^{1}$, Farshad Salamat-Zadeh ${ }^{2}$, Gaetano Brriesci ${ }^{1}$ \\ ${ }^{1}$ University College London (UCL), London, WC1E 6BT, United Kingdom \\ Rashmi.raju.13@ucl.ac.uk; g.burriesci@ucl.ac.uk \\ ${ }^{2}$ TWI Ltd, Granta Park, Great Abington, CB21 6AL, United Kingdom \\ Farshad.salamat@twi.co.uk
}

\begin{abstract}
Nitinol (NiTi), an equiatomic nickel-titanium alloy, is widely used in the medical field due to its unique properties such as superelasticity and shape memory effect. Nitinol alloy is sensitive to thermo-mechanical processing which leads to reduction in the superelasticity and shape memory effect at the joint. These thermo-mechanical processes are necessary in the manufacturing procedure which are involved in the construction of cardiovascular devices and implants. Most medical devices are currently obtained from lasercutting of nitinol tubes, or from assemblies of nitinol elements (e.g. wires) joined at specific locations by crimping. However, these approaches reduce the strength of the structure at the joints. The main objective of this study is to analyse the most common joining techniques adopted for nitinol-nitinol and optimise the joint. Preliminary experiments were conducted on superelastic nitinol wires of $0.44 \mathrm{~mm}$ diameter, employing resistance discharge welding and percussive arc welding processes. Successively, laser micro welding was tested, and resulted to provide superior joining properties, due to increased mechanical strength. Examination of the microstructure and microhardness of the welded specimens was carried out. The mechanical strength of the welded specimens was evaluated using tensile testing. An elemental study was performed using energy dispersive X-ray spectroscopy (EDS) to assess nickel and titanium concentration at the fusion zone. Differential scanning calorimeter (DSC) investigations was carried out to determine the phase transformation temperatures. The results suggest that the laser micro welding procedure preserves the pseudoelastic properties of laser welded specimens in comparison to the reference material. The proposed joining approach may enable further expansion in the use of the properties of nitinol in the medical area, and result in improvements in the safety and durability of cardiovascular implants.
\end{abstract}

Keywords: Cardiovascular implants, Joining medical devices, Nitinol, Shape-memory alloy, Superelastic, Laser welding

\section{Introduction}

Cardiovascular diseases (CVDs) are one of the most prominent cause of deaths in the aging population and it is estimated to increase in the future [1]. To tackle this problem, extensive studies are being carried out on the development of new and improved cardiovascular implants. Modern cardiovascular surgical procedures are moving away from open surgeries to minimally invasive surgeries (MIS) due to less healing time. MIS requires better and innovative devices that are smaller and works efficiently in complex vasculature [2-3]. These innovative devices, which include angioplasty stents, vascular plugs, filters, and transcatheter heart valve frames, are mainly made from nitinol alloys, due to their superelastic properties. Often, in order to reduce the manufacturing complexity of the device, it is advantageous to join the alloy to itself (e.g. in stent and stent graft applications); however this may represent a challenge, as long-term implantation in the human body requires metallurgical compatibility, weldability and preservation of the structural integrity of weld region under fatigue in a corrosive environment.

Laser micro welding is widely used to join nitinol parts, due to reduced size of the components [4]. This technique could replace currently used crimping processes as shown in Fig. 1. Laser welding does not use any fluxes, solvents, or additives, thus making this technique biocompatible. This technique provides flawless hermetic welds essential for cardiovascular applications. Clean laser welds result in products that are easier to sterilize or fit into other assemblies without weld seam interferences. Laser welding is suitable for high temperature sterilization and provide non-porous, sterile surfaces without any post-processing. The laser beam can access small joints that other welding technique cannot.

This paper reports result of experiments carried out to study the weldability of superelastic nitinol alloy using quasi continuous wave laser. Mechanical properties, microstructure, micro-hardness and transformation temperatures of the joints are characterised with respect to the reference material. 


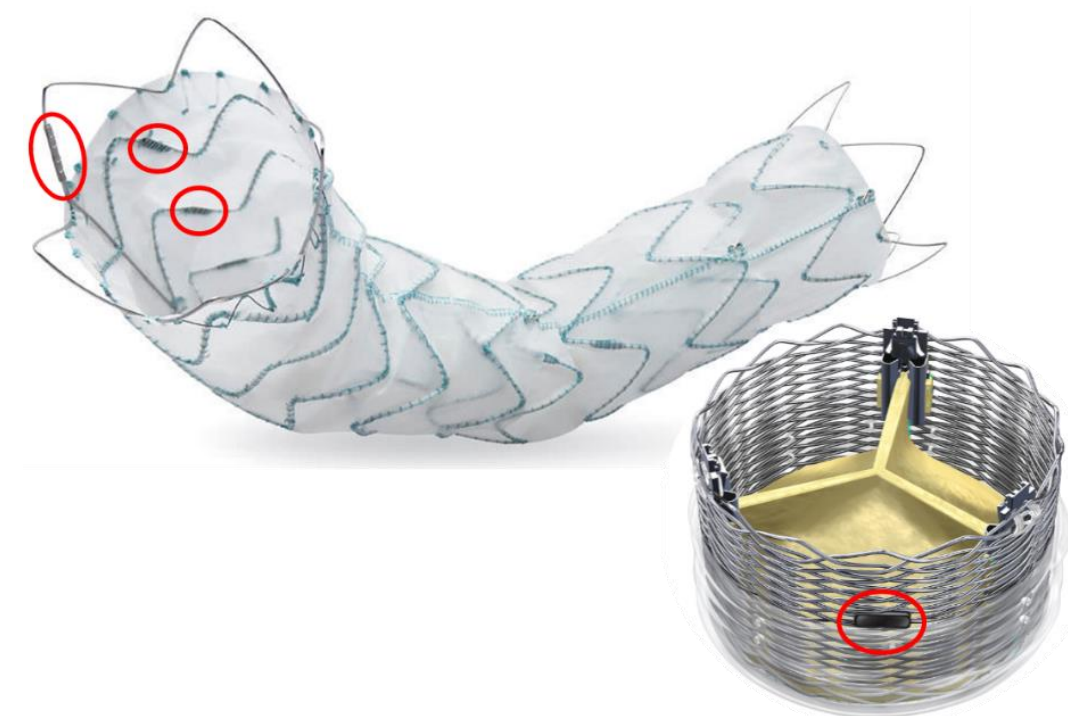

Fig. 1: Nitinol wires joined by crimping in a stent graft (Talent ${ }^{\circledR}$ Thoracic Stent Graft, Medtronic) and in a transcatheter heart valve (Lotus ${ }^{\mathrm{TM}}$ Valve, Boston Scientific Corporation). The crimping sleeves are indicated by the circles.

\section{Materials and Methods}

For this study, $0.44 \mathrm{~mm}$ superelastic nitinol wires (Memry, Germany) were used. This wires were chemically etched and straight annealed by heat treating at approximately $500{ }^{\circ} \mathrm{C}$ by the manufacturer. Resistance discharge welding of nitinol was carried out using a Cooperheat Thermocouple attachment unit. The equipment is generally used to attach thermocouples to components using capacitive discharge method. However, the trials were unsuccessful as the welds produced were not strong enough and failed during physical examination. Percussive arc welding of nitinol was carried out using an arc welded power unit. The nitinol wires were held between the clamps for joining. The joints formed during this process fractured during physical examination. Laser micro welding of Nitinol was carried out using quasi continuous wave (QCW) fibre laser, operating in continuous mode. To create the joint, wire sections of $50 \mathrm{~mm}$ length were fixed parallel to each other (overlap of 10mm each side) on an $x-y$ manipulator and were seam welded under argon shielding, to prevent oxidation during welding process. The beam was focused between the overlapped wires using build in camera. Fig. 2 shows the schematic of the laser welding set-up used in this study. Silver tapes were used to hold the wire in place during the welding process.

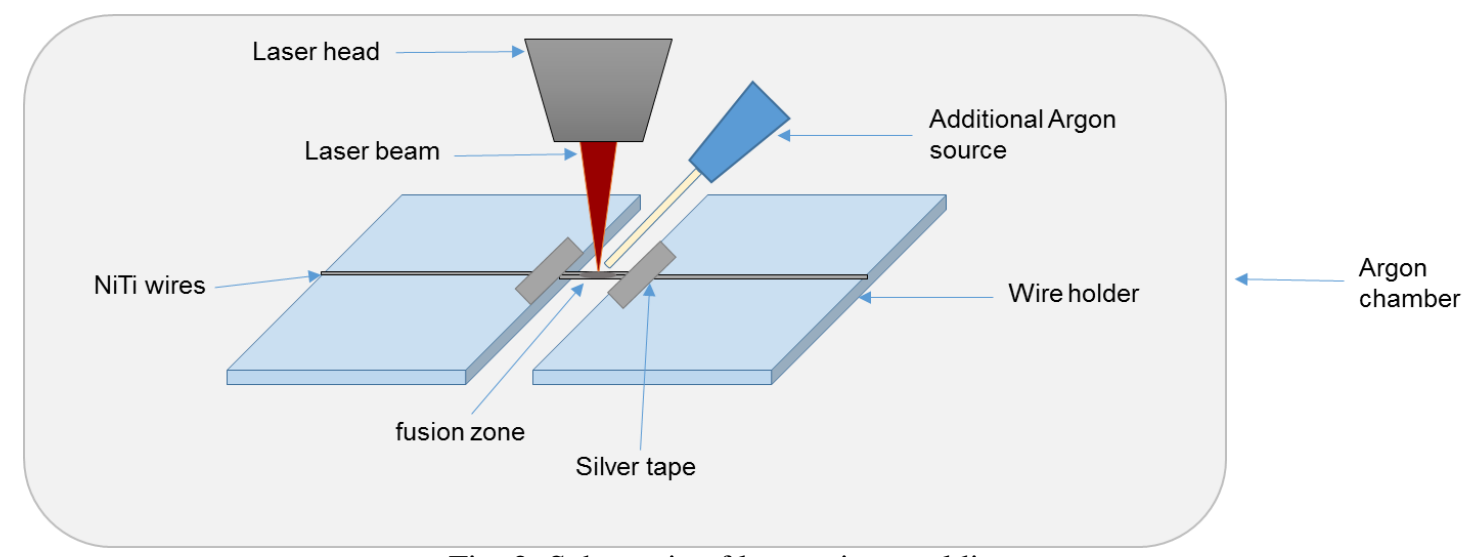

Fig. 2: Schematic of laser micro welding set up.

Mechanical tests of the laser micro welded Nitinol wires were carried out using uniaxial tensile testing procedure. The tests were carried out on a Zwick Roell machine with a cross-head speed of $0.5 \mathrm{~mm} / \mathrm{min}$ at room temperature $\left(\sim 22.0^{\circ} \mathrm{C}\right)$ and body temperature $\left(37^{\circ} \mathrm{C}\right)$. Details of specimen geometry and dimensions are given in Fig. 3. A minimum of 3 welded samples 
were tested and compared against as-received nitinol wire. Microhardness tests were carried out to evaluate the hardness of the fusion zone and heat affected zone (HAZ) compared to the reference material.

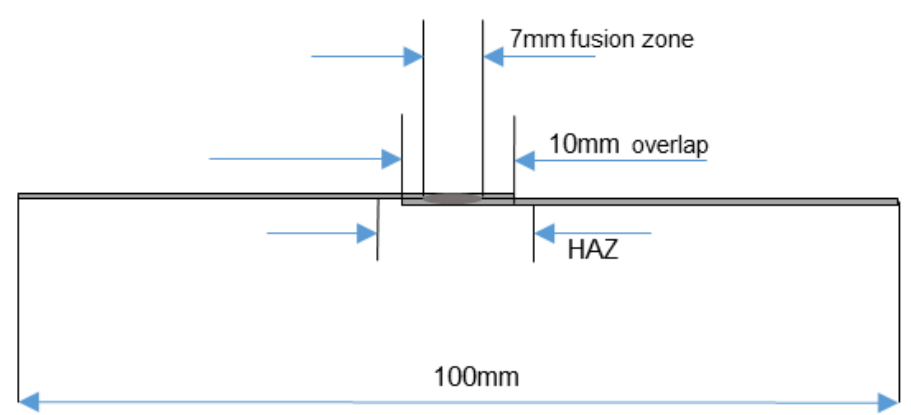

Fig. 3: Schematic of tensile specimen.

DSC measurements were carried out under a controlled linear cooling/heating rate of $5^{\circ} \mathrm{C} / \mathrm{min}$. The test specimen was initially cooled from room temperature $\left(\sim 22^{\circ} \mathrm{C}\right)$ to $-40^{\circ} \mathrm{C}$, heated to $200^{\circ} \mathrm{C}$ and cooled back to $-40^{\circ} \mathrm{C}$. Temperature calibration of the DSC apparatus was performed by running indium standard. The weld specimens were cut across the welded region in order to study the heat affected zone (HAZ). These investigations reveal the phase transformation temperatures for both reference and welded materials, in terms of martensite start $\left(M_{s}\right)$, martensite finish $\left(M_{f}\right)$, austenite start $\left(A_{s}\right)$, austenite finish $\left(\mathrm{A}_{\mathrm{f}}\right)$.

Scanning electron microscopic were examined to analyse the microstructure at the fusion zone, HAZ and parent material.

\section{Results and Discussions}

\subsection{Mechanical tests}

The welds produced by resistance discharge and arc percussive welding techniques both failed during physical examination which suggested that the welds were considerably weak, no further testing were carried out. However, laser micro welded proved to be better welding technique and therefore, further examination of the welds were carried out.

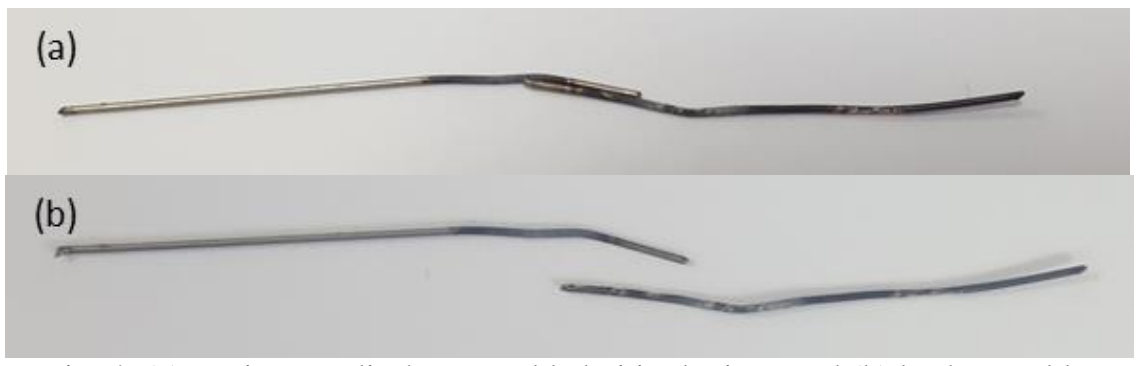

Fig. 4: (a) Resistance discharge welded nitinol wires, and (b) broken welds.

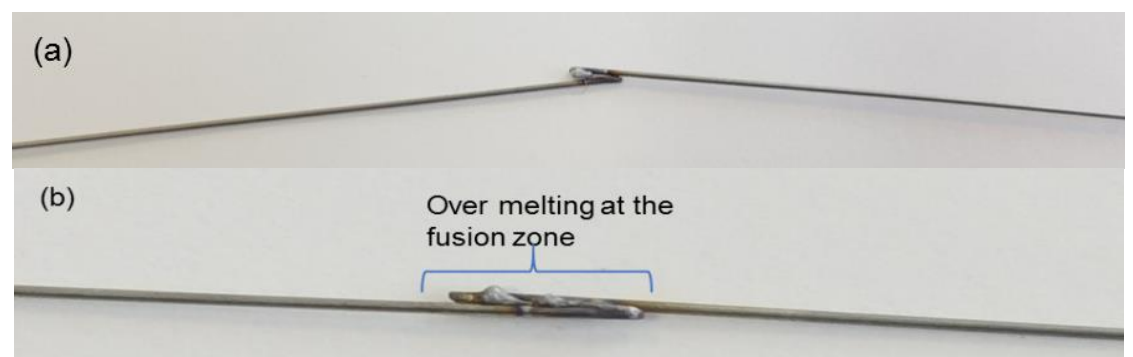

Fig. 5: (a) Percussive arc welded nitinol wires and (b) close-up of the welded region. 


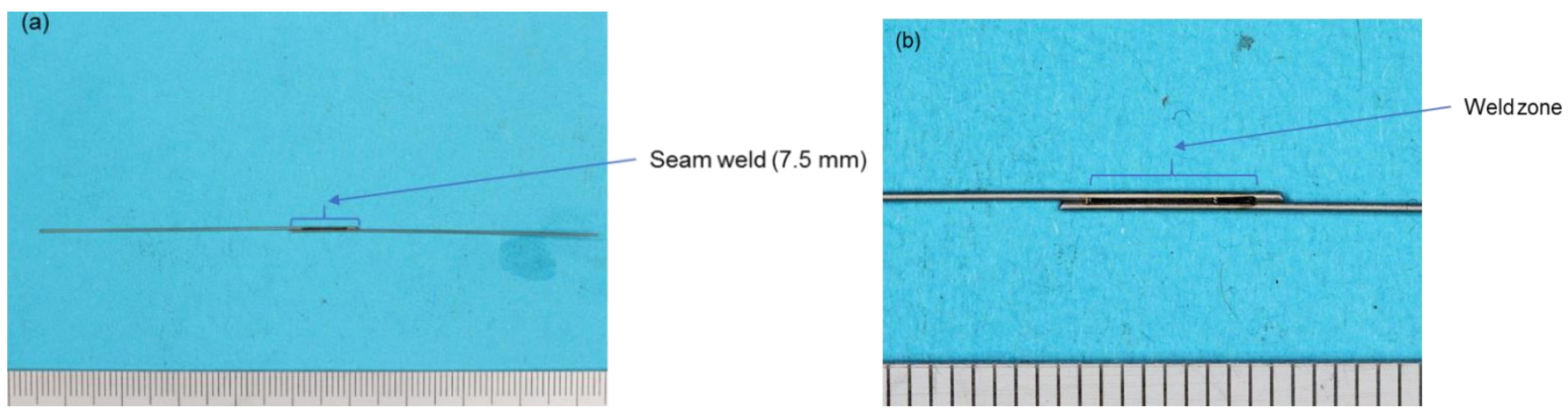

Fig. 6: (a) Laser micro welded nitinol wires and (b) close-up welded region.

The characteristic stress-strain curves from static tensile testing of reference superelastic material and laser micro welded nitinol are shown in Fig. 6. Tests were carried out according to the ASTM standard F 2516-07 ${ }^{2}$ (Test method for tension testing of nickel-titanium superelastic materials). The nitinol wire in its as-received condition (purple unbroken line) show the characteristic behaviour of superelastic alloy [4]. The nitinol-nitinol joint exhibits engineering stress-strain behaviour comparable to the reference material. The formation of a plateau at a stress of approximately $500 \mathrm{MPa}$ and strains from about 2 to $9 \%$ can be observed. With further increase of strain the wires deforms following the martensitic Young's modulus and, after reaching its plastic region, fracture. The rupture stress reaches only $70 \%$ of the level measured for the reference material. The joint usually fails at the HAZ, as laser micro welding has shifted the fatigue point from the fusion zone to the HAZ.

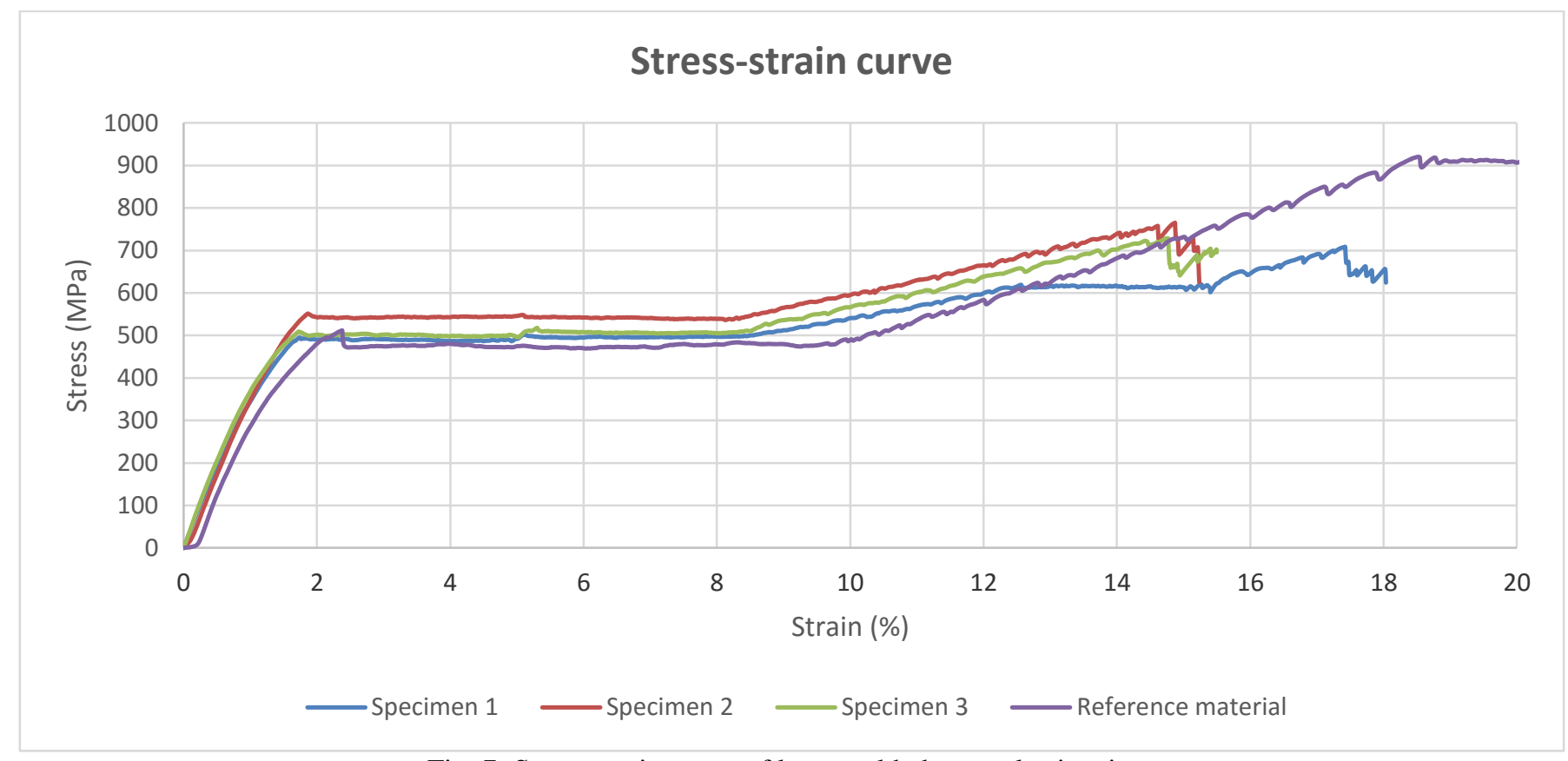

Fig. 7: Stress-strain curve of laser welded superelastic wires.

\subsection{Scanning electron microscopy of the microstructure}

Microstructure of the fusion zone and parent material show similar surface morphology, indicating that the laser processing does not affect the microstructure of the material significantly as shown in Fig. 8. The nitinol-nitinol fusion zone shows some significant coarse grains as observed by SEM however fusion boundary shows epitaxial crystallization of the grains due to laser welding [4]. 

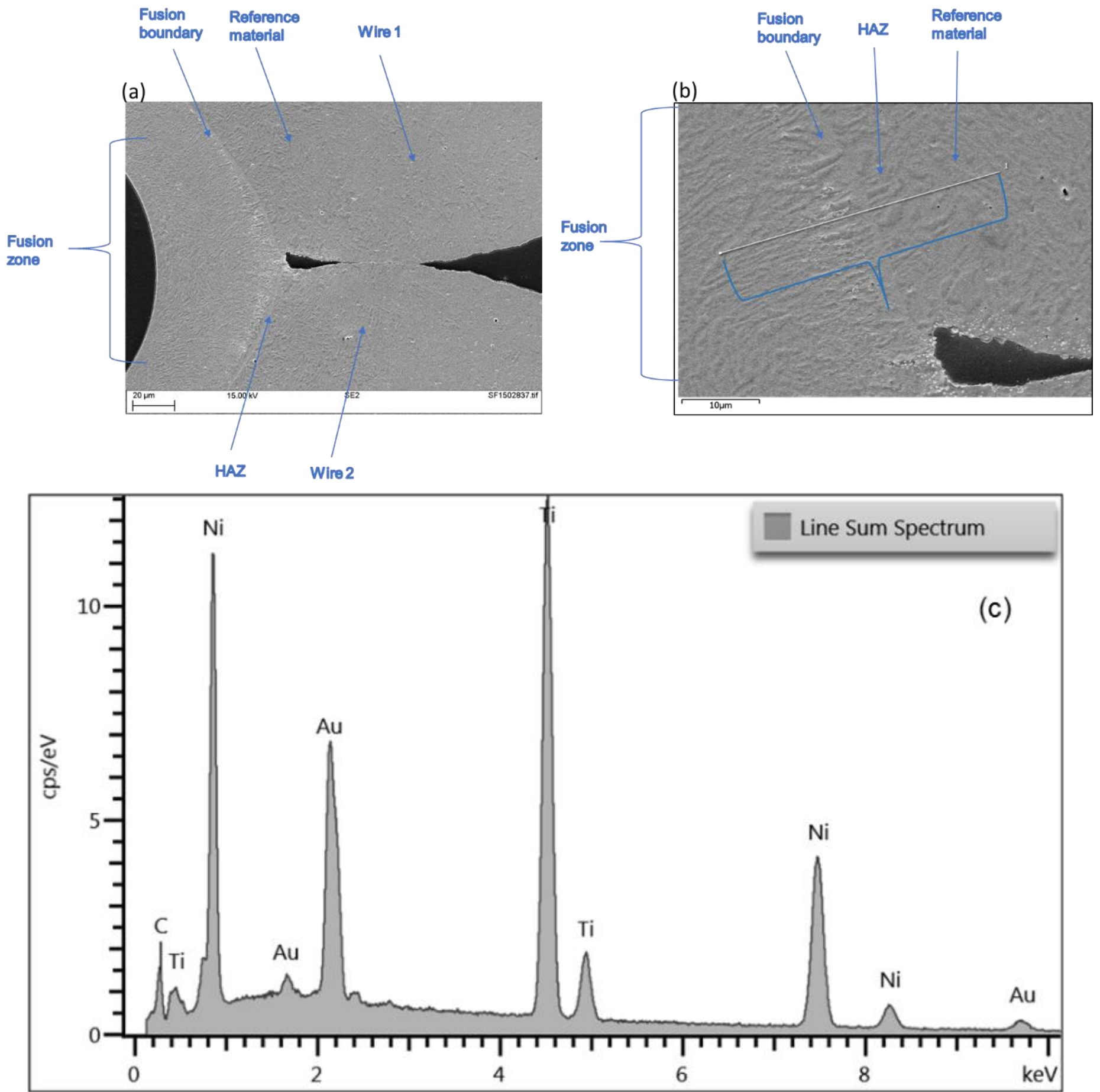

Fig. 8: (a) SEM scans of (a) laser welded nitinol wire, and (b) close-up of fusion boundary, and (c) line scan of fusion zone, HAZ and reference material.

Energy dispersive x-ray spectroscopy (EDS) scans as described in Fig. 8 (c) and 9 shows no variance in nickel and titanium concentration across the welded region, HAZ and reference material, confirming the absence of any foreign particles on the surface. The presence of carbon (C) peaks indicate presence of contamination. The gold (Au) peaks found on the spectrum are from gold coating of the sample surface prior SEM procedure. 


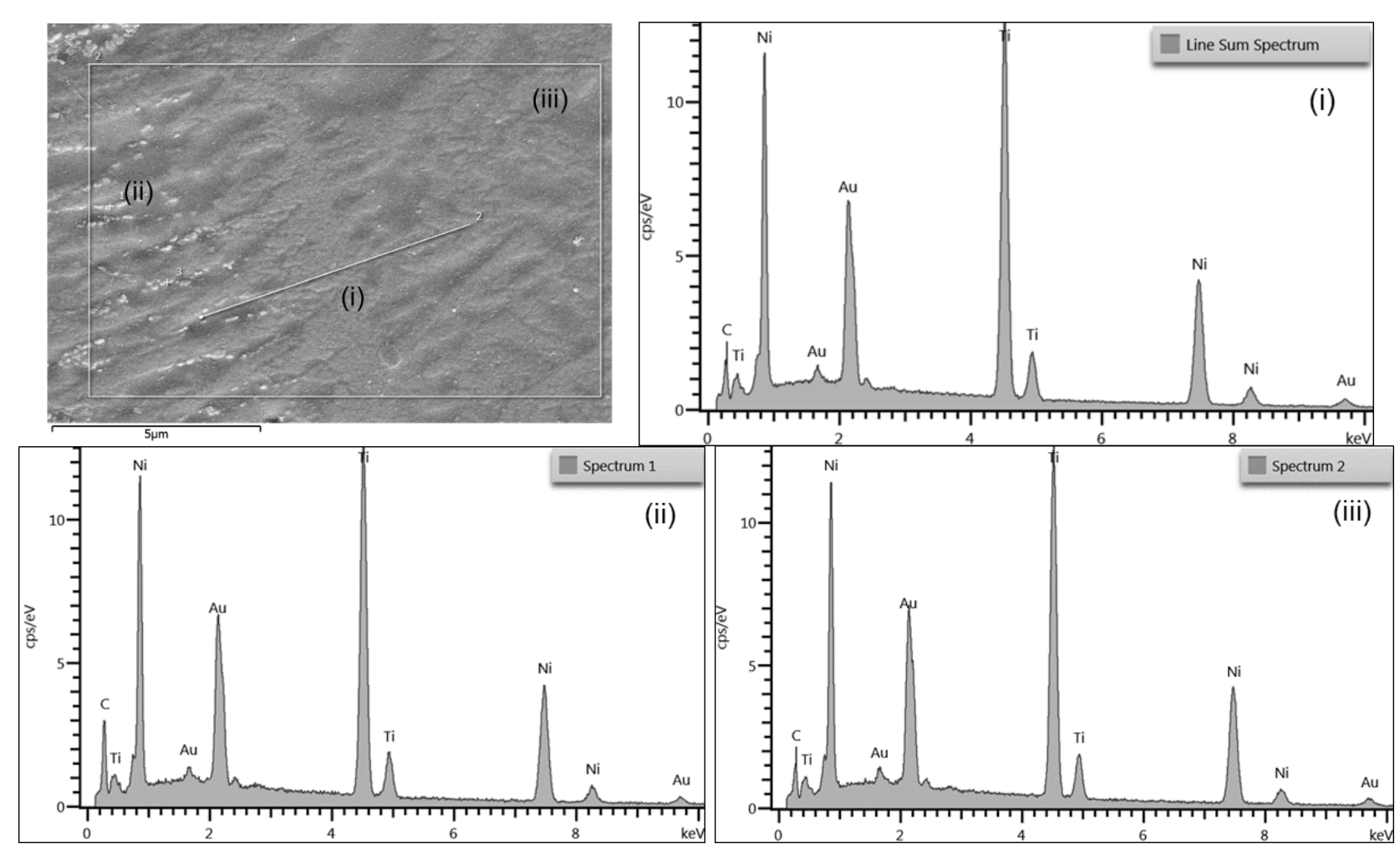

Fig. 9: EDS scans of laser welded nitinol where (i) line scan across fusion zone, fusion boundary and HAZ, (ii) point scan of fusion zone, and (iii) point scan of HAZ.

\subsection{Microhardness tests}

Microhardness tests were carried out Tests were carried out according ASTM standard E384-11 ${ }^{1}$ (Standard Test Method for Knoop and Vickers Hardness of Materials). The microhardness profiles is plotted in Fig. 10 which provides the information from the test, indicating $22 \%$ decrease in the material hardness from 349 to $271 \mathrm{HV}$ due to resolidification structure of the weld zone. Cold working of the wire was eliminated due to heat from the laser welding which in turn resulted in softening of the wire. The hardness values increases continuously from the fusion zone (FZ) to the reference material (RefM), despite some variations on the measured values. Heat from the laser welding process recrystallises the grains, which may influence the hardness of that region by reducing the hardness profile at the fusion zone and HAZ [5].

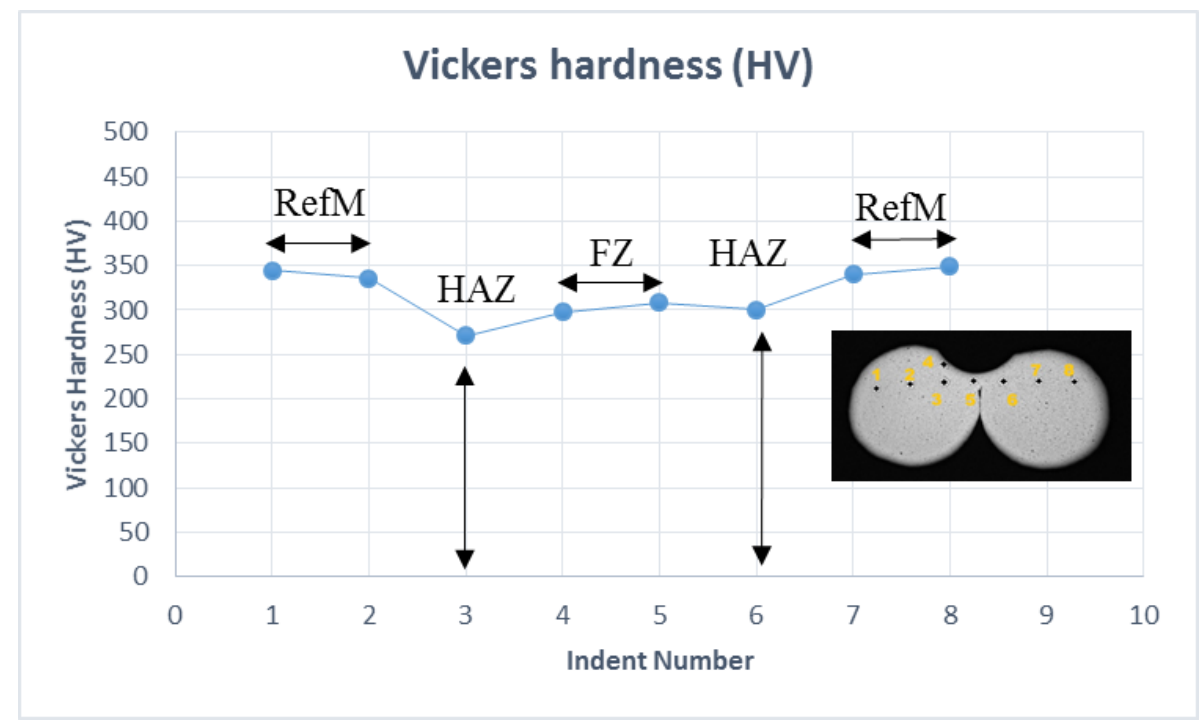

Fig. 10: Microhardness profile of laser welded nitinol across the indented surface. 


\subsection{Differential Scanning Calorimetry (DSC)}

Differential scanning calorimetry (DSC) curves shows similar high and low temperature peaks suggesting that the thermomechanical properties of nitinol are not substantially altered during laser welding process. Further examination is required to understand the processing effect on nitinol properties. Cold worked wires have higher transformation temperature as they require higher activation energy to overcome the stress induced by random dislocation [6-8]. The reduction in the transformation temperature in Fig. 11 is due to annealing of the material prior welding [9]. Nitinol implant with a transition temperature of $15{ }^{\circ} \mathrm{C}$ or less can be fully deployed at room temperature and therefore they are constrained in the delivery system before introducing them in the body to take their expanded operating shape [10].

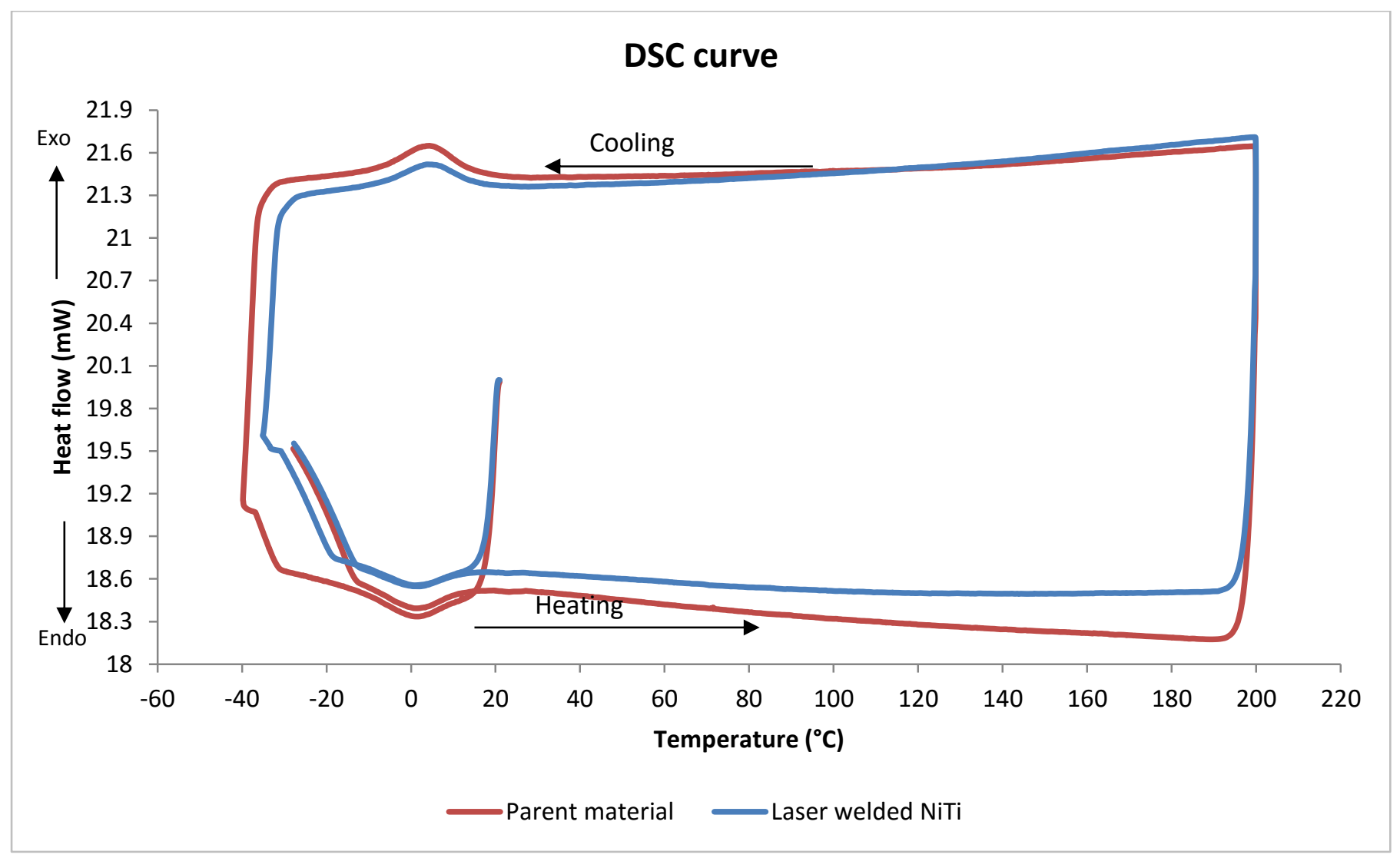

Fig. 11: DSC curve of laser welded and parent nitinol.

\section{Summary and Conclusions}

Laser micro welding proved to be a successful joining process for the nitinol wires due to increased mechanical strength compared to resistance discharge and arc percussive welding. SEM was used to analyse the surface morphology of laser welded nitinol wires. The microstructure and microhardness of the welded nitinol wires were investigated by studying the mechanical properties, microstructures and phase transformation. Removal of surface contaminants resulted important to laser welding of nitinol, as entrapment of contaminants can reduce the mechanical strength of the weld. Fatigue tests needs to be carried out to determine the durability of the material.

A structurally critical region of current cardiovascular implant is the joint between nitinol-nitinol and nitinolbiopolymers. New and emerging techniques such as laser micro welding and ultrasonic welding will help to mitigate the current limitations, substantially improving the joint strength and the safety of the devices. Enhancing the joining technique may provide better welds which will help in defining next generation healthcare and contribute to will improve the performance of new generation cardiovascular implants.

\section{Acknowledgements}

This study was supported by an EPSRC, UK Industrial Case Studentship with industrial contribution from TWI, Ltd. 


\section{References}

[1] S. Allender and M. Rayner. (2014, October 02). Coronary heart disease statistics: British Heart Foundation, Heart Statistics, 2007. [Online]. Available: www.bhf.org.uk/heart-health/statistics.aspx

[2] C. Song, "History and current situation of shape memory alloys devices for minimally invasive surgery," J Open Med. Dev., vol. 2, pp. 24-31, 2010.

[3] P. Qi, M. F. Maitz, and N. Huang, "Surface modification of cardiovascular materials and implants," Surf and Coatings Tech, vol. 233, pp. 80-90, 2013.

[4] S. K. Sadrnezhaad and S. H. Mirabolghasemi, "Optimum temperature for recovery and recrystallization of 52Ni48Ti shape memory alloy," Mat. \& Designs, 28, no. 6, pp. 1945-1948, 2007.

[5] H. Gugel, A. Schuermann, and W. Theisen, "Laser welding of Nitinol wires," Mat Sci and Eng A., vol. 481-482, pp. 668-671, 2008.

[6] K. Kuita, H. Matsumoto, and H. Abe, "Transformation behaviour in rolled Nitinol," J. Alloys Comp, vol. 381, no. 1-2, pp. 158-161, 2004.

[7] D. A. Miller and D. C. Lagoudas, "Influence of cold work and heat treatment on the shape memory effect and plastic strain development of Nitinol," Mater. Sci. Eng. A., vol. 308, no. 1-2, pp. 161-175, 2001.

[8] H. Matsumoto, "Transformation behaviour of Nitinol in relation to thermal cycling and deformation," Physica B, vol. 190, no. 2-3, pp. 115-120, 1993.

[9] M. I. Khan and Y. Zhou, "Micro-welding of shape memory alloys," in Joining and Assembly of Medical Materials and Devices, Y. Zhou \& M. D. Breyen, Ed. Woodhead Publishing, 2013, pp. 133-153.

[10] Stoeckel, "Nitinolnol-A Material with unusual properties," EndoVas. Update. Is. 1, pp. 1-5, 1998. 